\title{
Operational verification of a framework for the probabilistic nowcasting of river discharge in small and medium size basins
}

\author{
F. Silvestro and N. Rebora \\ CIMA Research Foundation, Savona, Italy \\ Correspondence to: F. Silvestro (francesco.silvestro@cimafoundation.org)
}

Received: 22 September 2011 - Revised: 14 February 2012 - Accepted: 15 February 2012 - Published: 23 March 2012

\begin{abstract}
Forecasting river discharge is a very important issue for the prediction and monitoring of ground effects related to severe precipitation events. The meteorological forecast systems are unable to predict precipitation on small spatial (few km) and temporal (hourly) scales. For these reasons the issuing of reliable flood forecasts is not feasible in those regions where the basin's response to rainfall events is very fast and can generate flash floods. This problem can be tackled by using rainfall nowcasting techniques based on radar observations coupled with hydrological modeling. These procedures allow the forecasting of future streamflow with a few hours' notice. However, to account for the shortterm uncertainties in the evolution of fine scale precipitation field, a probabilistic approach to rainfall nowcasting is needed. These uncertainties are then propagated from rainfall to runoff through a distributed hydrological model producing a set of equi-probable discharge scenarios to be used for the flood nowcasting with time horizons of a few hours. Such a hydrological nowcasting system is presented here and applied to some case studies. A first evaluation of its applicability in an operational context is provided and the opportunity of using the results quantitatively is discussed.
\end{abstract}

\section{Introduction}

The phase of monitoring of the severe precipitation events is a fundamental part of the work of hydro-meteorologist involved in Civil Protection activities. During the days before the event, the forecast systems are used as support to understand and evaluate the severity of the upcoming event and to decide if it is necessary to issue an alert. This kind of forecast is usually made for the following 24-72 $\mathrm{h}$.

The small scale precipitation structures are still impossible to predict with sufficient precision in terms of spatialtemporal localization and intensity (Droegemeir et al., 2000; Roberts, 2008). In the small catchments flood forecast process, it is only possible to reliably predict the large scale structure of precipitation but not the occurrence at basin scale (Siccardi et al., 2005; Silvestro et al., 2011).

With the start of the flood-triggering precipitation, the availability of a flood forecast with a time horizon of around $6 \mathrm{~h}$ becomes crucial. This is particularly valid in the case of small and medium-size basins that have reduced response time and can produce flash floods.

When the basin response time is of the order of few hours, the usefulness of the aforementioned flood forecast is generally related to the assumption that an alert message has been previously issued so that the various institutional levels of the Civil Protection are ready to operate. Otherwise, the social response time $\left(t_{\mathrm{s}}\right)$ could be of the order or larger than the response time of the basin $\left(t_{\mathrm{b}}\right)$ (Siccardi et al., 2005; Creutin et al., 2009). Only very organized and prepared authorities and communities (e.g. municipalities) succeed in reacting in a shorter time $\left(t_{\mathrm{s}}<t_{\mathrm{b}}\right)$.

The scientific community is working hard to produce reliable quantitative precipitation forecast on time horizons of 6-8 $\mathrm{h}$ and small spatial scales by using data assimilation techniques for example (Rossa et al., 2010), but currently there are no stable and well tested approaches which can be used in an operational context.

The use of rainfall observations is still the main starting point when predicting precipitation with time horizons of a few hours. Meteorological radars permit the capture of the rainfall spatial structure and a great number of algorithms have been designed to predict future rainfall based on the most recent available observations (Seed, 2003; Germann and Zawadski, 2002; Li and Schmid, 1998); these procedures are commonly called nowcasting systems. They provide a precipitation forecast that, in some cases, can be quite reliable in a time horizon of $1-3 \mathrm{~h}$. However, when strong orographic and/or convective effects are present together with growth and decay of rainfall cells, they often fail in correctly predicting future occurrence. 
Some nowcasting techniques like GANDOLF (Pierce et al., 2000) and Nimrod (Golding, 1998) try to combine radar data with satellite data and meteorological models, but the results are not always better than using radar information alone.

Previous studies have investigated the improvements based on the use of radar rainfall estimation as input into rainfall-runoff models, in order to produce simulated hydrographs (Pessoa et al., 1993; Borga, 2002; Kouwen et al., 2004). Recently some works have been done with the same aim but following a probabilistic approach (Germann et al., 2009).

Other authors have tried to couple nowcasting techniques and hydrological models with the objective of extending the lead time of hydrological forecast by improving the knowledge of future rainfall (Berenguer et al., 2005; Vivoni et al., 2006; Vivoni et al., 2007; Salek et al., 2006).

Berenguer et al. (2005) presented a detailed study of the improvements and the limits of using a nowcasting algorithm to predict rainfall in respect to the application of eulerian or lagrangian persistence to the most recent observations.

In this work we try to advance the work of these latter authors, carrying out a similar objective but mainly with two new elements: (i) the perspective of the application in an operational context, (ii) the introduction of a probabilistic approach. This last point is quite new since only a few works about the use of an ensemble of nowcasted rainfall fields as input of rainfall-runoff models have been carried out (Achleitner et al., 2008; Kim et al., 2009; Schröter et al., 2011).

The proposed approach is based on the coupling of a stochastic nowcasting algorithm with a rainfall-runoff model, the result is a framework that allows the production of an ensemble of discharge scenarios. The adopted nowcasting technique accounts for the uncertainties related to the forecasted rainfall fields; these uncertainties are propagated by the rainfall-runoff model in order to evaluate how they affect the streamflow prediction.

Many works have been devoted to studying the effects of the uncertainties of radar rainfall estimations when they are used as input into a rainfall-runoff model as well as the effects due to the rainfall-runoff model's uncertainties (Carpenter and Georgakakos, 2006a, b; Schröter et al., 2011). The work we present focuses on the attempt to account for the uncertainties related to the rainfall predictions obtained by the nowcasting algorithm.

The article is organized as follows: in Sects. 2 and 3, the study area and the hydrological nowcasting framework are described, Sect. 4 furnishes a description of the verification methodology. The application and the results are discussed in Sect. 5 while in Sect. 6, discussion and conclusions are presented.

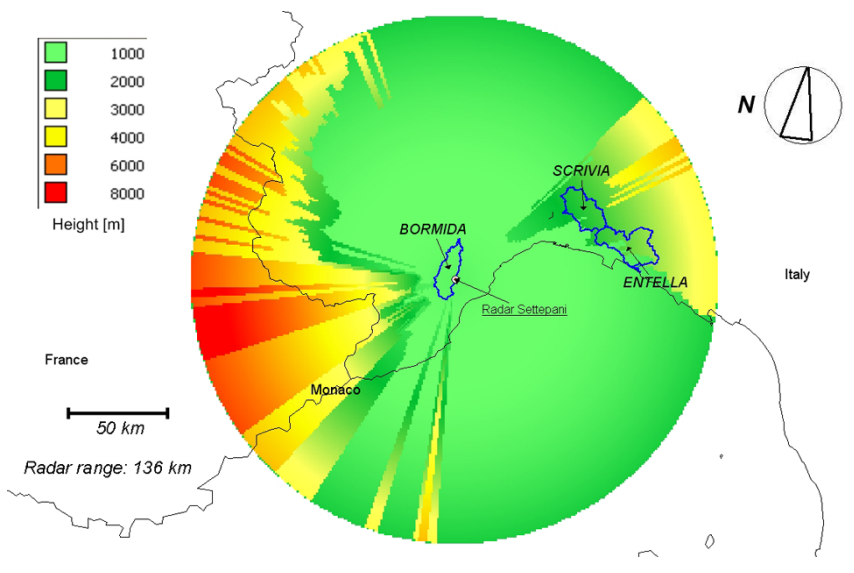

Fig. 1. Study area. The Settepani radar location is reported together with the height of visibility at each point of the area covered. The three basins with a drainage area larger than $150 \mathrm{~km}^{2}$ are reported. Minor basins are located between Bormida and Entella basins, in an area where the height of visibility is generally lower than 2000$2500 \mathrm{~m}$.

\section{Study area}

The hydrological nowcasting system has been applied in the Italian Region of Liguria which is characterized by a mountainous topography with the Apennines in the eastern part of the region and Alps in the West. These are mountains with a height ranging up to $2000 \mathrm{~m}$ that decreases rapidly to sea level with steep slopes. A very high percentage of the territory is covered by forests (about $70 \%$ ) and the main urban areas and towns have been established along the coast, often at the mouth of rivers. The majority of the basins have a drainage area in the interval $10^{1}-10^{2} \mathrm{~km}^{2}$, with rapid response time (maximum few hours), and the region is hit by Mediterranean perturbations that often have quite a short duration (12-36h) and high rainfall intensities (Deidda et al., 1999; Boni et al., 2007). These two factors contribute to create flash floods which can cause damage to properties and jeopardize the safety of the citizens. New forecasting techniques (Cloke and Pappenberger, 2009; Silvestro et al., 2011) help to predict the probability of occurrence of these types of flood events with a good level of reliability. However, their correct and precise localization are still impossible to predict with sufficient anticipation time (12-36 h before the event). During the monitoring and the nowcasting of the event, the hydrologists can look at the real evolution of the perturbation and only at this moment, the uncertainty of localization reduces to a level coherent with small-medium size basin scale.

The Liguria Region is covered by a Doppler polarimetric C-band radar, placed on Settepani mountain at an height of $1386 \mathrm{~m}$ (Fig. 1).

The primary scan, used for QPF estimation, has the characteristics reported in Table 1. 
A dense automatic micrometeorological network of about 120 rain gauges covers the region, providing rainfall data in real-time with a time resolution of 5-10 min.

\section{Hydrological nowcasting framework}

The proposed framework is a technical system composed of different algorithms and techniques which allow the final objective to be reached: the probabilistic nowcasting of river discharge.

It is mainly made up of three components: (i) a technique for observed rainfall estimation by using radar and rain-gauge data, (ii) an algorithm for probabilistic nowcasting of precipitation fields and (iii) a rainfall-runoff model. In the following paragraphs the three elements will be briefly described.

The rainfall scenarios are composed of two different parts: the observed rainfall (from the beginning of the event to the time of last available observation) and the nowcasted rainfall.

The greater part of a rainfall scenario is constituted by observed rainfall (see Fig. 2), while a reduced portion only is made by nowcasted rainfall; consequently, it is evident that the good estimation of the observed part of rainfall events is fundamental to the performance of a nowcasting system and it is necessary, therefore, to provide the system with the best possible rainfall estimation.

It is clear that nowcasting systems based only on radar information rarely furnish reliable forecasts beyond $2-3 \mathrm{~h}$ (Keenan et al., 2003; Ebert et al., 2004). This reflects on hydrological applications as demonstrated in Berenguer et al. (2005).

The presented methodology is different from many other systems that couple a nowcasting algorithm with a hydrological model for generating a discharge forecast because a probabilistic nowcasting algorithm is now introduced. In this way, it is possible to produce an ensemble of forecasted scenarios and not a unique deterministic one.

The availability of a wide range of possible occurrences in terms of streamflow can increase the information to a hypothetical forecaster, giving also a measure of the uncertainty associated to the forecast itself.

This is a very important issue, particularly when we deal with small and medium size basins. Small localization errors of rainfall fields caused by the nowcasting algorithm can lead to large errors in the forecasted discharge. In the case of large basins this effect is reduced because the basin itself integrates the precipitation input. We expect, therefore, that for the same error of localization on the forecasted rainfall, the impact on the discharge simulation on a small basin is greater than that on a large basin.

In the following paragraphs the three elements of the framework are briefly described.

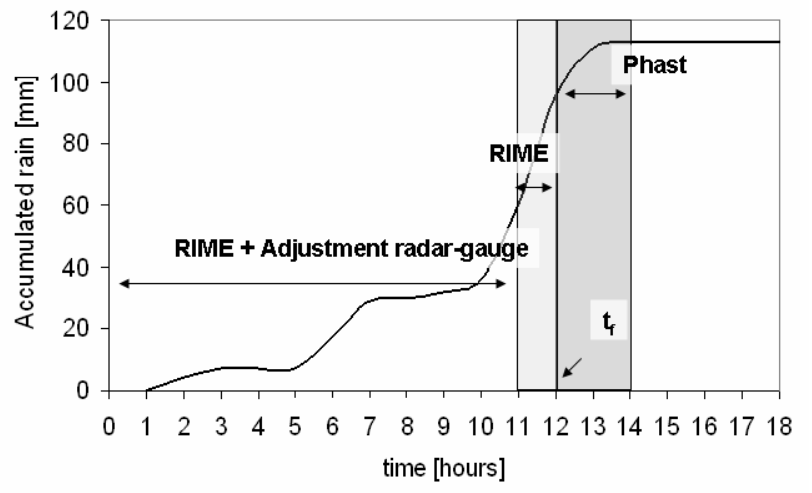

Fig. 2. Reference schematization for the building of a rainfall scenario. The first part is generated using the algorithm RIME and the radar-gauge adjustment; the hour before the forecast time $\left(t_{\mathrm{f}}\right)$ is generated using only radar observations (RIME) and the nowcasted part using the algorithm PhaSt.

\subsection{Rainfall estimation}

Rainfall is estimated by using data from multiple sensors, including a polarimetric radar and rain gauges. Since we use data from a polarimetric radar, we employed an algorithm named RIME, which uses the polarimetric variables as input; this is described in Silvestro et al. (2009). It is a flow chart algorithm that employs different sets of radar variables that depend on the values of the variables themselves; the aim is to use the optimal measured variables for calculating the precipitation. It is possible to summarize the algorithm with the generic function:

$R=f\left(Z_{H}, Z_{\mathrm{DR}}, K_{\mathrm{DP}}\right)$

where $R$ is the rainfall intensity, $Z_{H}$ the reflectivity, $Z_{\mathrm{DR}}$ the differential reflectivity and $K_{\mathrm{DP}}$ the specific differential phase.

The algorithm makes it possible to estimate the rainfall intensities (rain-rate) using data from each scansion (5 or $10 \mathrm{~min}$ ) by exploiting all the capabilities of the Settepani radar.

The rain-rate fields are then accumulated to an hourly scale and an algorithm of radar-gauge adjustment is applied. In this way a part of the advantages of having rainfall data at high time resolution is lost, but the objective is to try to obtain the best possible quantitative estimation on a still high temporal scale. The methodology employed is similar to the one described in Koistinen and Puhakka (1981) which provides the estimation of a corrective factor for each point of the radar rainfall field:

$a^{c}=a(d, H, H V)+\exp \left(-\frac{d_{\mathrm{m}}}{1.5 \rho}\right)\left(a^{\mathrm{G}}-a(d, H, H V)\right)$

where the term $a^{\mathrm{G}}$ depends on the density of rain gauge network and the actual measures while the term $a(d, H, H V)$ 
Table 1. Characteristics of the radar Settepani primary scans.

\begin{tabular}{lll}
\hline Characteristic & $\begin{array}{l}\text { Before } \\
\text { January 2010 }\end{array}$ & $\begin{array}{l}\text { After } \\
\text { January 2010 }\end{array}$ \\
\hline Maximum range $(\mathrm{km})$ & 136 & 134 \\
Prf $(\mathrm{Hz})$ & 1100 & 1040 \\
Radial resolution $(\mathrm{m})$ & 300 & 340 \\
Temporal resolution (min) & 10 & 5 \\
Measured variables & $Z_{H}, Z_{\mathrm{DR}}, \phi_{\mathrm{DP}}, \rho_{H V}\left(\right.$ lag 1), $V_{r}$ & $Z_{H}, Z_{\mathrm{DR}}, \phi_{\mathrm{DP}}, \rho_{H V}($ lag 1$), V_{r}$ \\
\hline
\end{tabular}

depends on the distance of the point from the radar $(d)$, on the height of terrain $(H)$ and on the height of visibility of the radar $(H V), d_{\mathrm{m}}$ is the mean distance between the rain gauges used for adjustment and $\rho$ is the linear dimension of the area around the analyzed location. The term $a(d, H, H V)$ replaces the term $a(d)$ of the original formulation that depends only on the distance $d$ and it is estimated following Gabella et al. (2001) as:

$$
a(d, H, H V)=a_{0}+a_{D} \cdot \log (D)+a_{H V} \cdot H V+a_{H} \cdot H
$$

The parameters $a_{0}, a_{D}, a_{H V}, a_{H}$ have a sort of climatologic meaning and are estimated through a non linear multiple regression using pairs of radar-gauge data from a set of rainfall events. The term $a(d, H, H V)$ is thus calibrated basing on the specific study area and on the specific radar system.

The coefficient $a^{\mathrm{c}}$ is estimated for each grid cell and the final rainfall map $\mathbf{R}_{T}$ is calculated as:

$\mathbf{R}_{T}=\mathbf{A} \times \mathbf{R}_{1 \mathrm{H}}$

where $\mathbf{R}_{1 \mathrm{H}}$ is the one hour accumulated rainfall map obtained using only radar estimation and $\mathbf{A}$ the matrix of correction coefficients.

\subsection{Probabilistic nowcasting algorithm: PhaSt}

PhaSt (Metta et al., 2009) is a rainfall nowcasting method based on the combination of an empirical non-linear transformation of measured precipitation fields and the stochastic evolution in spectral space of the transformed fields. An initial phase-velocity $\varpi$ is obtained from a 2-D FFT of two successive observed precipitation fields. This phase velocity is evolved as a Langevin process. In the following we report the main equations of the algorithm:

$$
\left\{\begin{array}{l}
k_{s}=\sqrt{k_{x}^{2}+k_{y}^{2}} \\
d \phi_{k_{s}}=\omega_{k_{s}} \mathrm{~d} t \\
d \omega_{k_{s}}=-\frac{\left(\omega_{k_{s}}-\omega_{k_{s}}^{\prime}\right)}{T_{s}} \mathrm{~d} t+\sqrt{\frac{2 \sigma_{s}^{2}}{T_{s}}} k_{s} d W
\end{array}\right.
$$

where $\phi_{k S}$ is the spectral phase, $T_{S}$ is the decorrelation-time, $\sigma_{s}^{2}$ is the variance of the process, $k_{x}$ and $k_{y}$ the wave numbers and $d W$ a is a random increment drawn from a normal distribution with zero mean and second-order moment ( $W$ is a Wiener process). The time gap between two rainfall fields depends on the radar scan strategy and in this application it is five or ten minutes.

The algorithm works as follows:

1. it starts from the last two rainfall maps provided by the meteorological radar,

2. gaussianizes them, take the Fourier transform of these fields, and

3. estimates the evolution of the Fourier phases between the two observations and generates an ensemble of possible future evolutions of the rainfall field according to the assumptions made in Eq. (5).

In this framework, the ensemble fields generated by the PhaSt procedure at $t=0$, will be equal to the last available radar map and they will evolve in time differently with differences that increase as the lead time increases, simulating in this way the uncertainties in the nowcasting process. The last of the Eq. (5) that describes the evolution of Fourier phases is based on two terms; the first one is deterministic and drives the average evolution common to all the ensemble fields, while the second term introduces a random increment that accounts for the uncertainties in the prediction. The model parameter that controls this stochastic term is $\sigma$ : if $\sigma=0$ the evolution is purely deterministic and all the ensemble members are equal, while as $\sigma$ increases the stochastic term introduces more noise and generates an ensemble whose spread is proportional to the value of $\sigma$.

After fixing the $T$ and $\sigma$ parameters, either by a direct estimation from a recent sequence of observed fields or by choosing them from a library (possibly conditioned on largescale synoptic conditions), a number of realizations of the precipitation process can be built. The result is an ensemble of nowcasted stochastic fields. Metta et al. (2009) reported some applications and verifications of the algorithm through the use of classic skill estimator (e.g. POD, CSI).

In this application, we chose the values of the parameters by trying to find a balance between over-representation and under-representation of uncertainty in terms of streamflow. The objective was to obtain a reasonable variability of discharge scenarios to represent the future possible occurrence, while at the same time avoiding the production of a spread 
of predicted streamflows that is too large and therefore useless. This is a sensitive point and further investigation could be carried out to analyze the effects of the parameters' variation.

\subsection{Rainfall-runoff model: DRiFt}

DRiFt (Discharge River Forecast) is a linear, semi-distributed event scale model based on a geomorphologic approach (Giannoni et al., 2000, 2005). The model is focused on the efficient description of the drainage system in its essential parts: hillslopes and channel networks. These are addressed by using two cinematic scales which determine the base of the geomorphologic response of the basin. The implemented infiltration scheme (Gabellani et al., 2008) allows the modeling of "multi-peak" events; in fact it is possible to simulate quite long periods (5-8 days) during which different events can occur. The propagation of water in the first soil layer is described and in this way, an auto initialization of the model is reproduced between an event and another. The schematization is valid and applicable when the simulation period is not too long and the evapotranspiration does not become crucial in the mass balance equation.

The discharge at any location along the drainage network can be mathematically formalized as follows:

$Q(t)=\int_{B} M\left(t-\frac{d_{0}(x)}{v_{0}}-\frac{d_{1}(x)}{v_{1}}, x\right) \mathrm{d} x$

where: $B$ is the drainage basin above the specified location $M(t, x)$ is the runoff rate at time $t$ and location $x, d_{0}(x)$ denotes the distances from $x$ to the closest stream channel and $d_{1}(x)$ denotes the distance from the stream channel closest to $x$ and the outlet, $v_{0}$ and $v_{1}$ are the hillslope and channel velocities. The basin is discretized in cells basing on a Digital Elevation Model and the two velocities define a corrivation time for each cell. The runoff estimated at cell scale is routed to the outlet section without accounting for the storage in the channels and without re-infiltration.

\section{Verification methodology}

The main objective of this work is to evaluate the functioning of a hydrological nowcasting system in an operational context. A technique for making a comparison between the simulated hydrographs and the reference hydrograph is needed. The task is to understand if the methodology allows the prediction of the discharge in a defined outlet section with a certain anticipation. We chose the output flow obtained by using the observed rainfall as input to the rainfall-runoff model as the reference hydrograph (Borga, 2002; Vieux and Bedient, 2004). In this way we separate the errors caused by the hydrological nowcasting technique with those which are due to bad calibration of rainfall-runoff model. To give an idea of the overall functioning of the system we also show the observed peak flows when they are available.

Berenguer et al. (2005) built the forecasted hydrograph using the rainfall-runoff model with an anticipation $\tau$ at each time step of the event, following the analysis of the multiplestep-ahead forecast (WMO, 1992). The generated hydrograph shows the flow forecasted by the system with a certain lead time. In Vivoni et al. (2006, 2007), other techniques are used to verify the benefits of using rainfall forecasts with different lead times as input in a hydrological model.

In our case, the comparison between a forecasted hydrograph and a reference hydrograph can't be carried out; it should be made, however, between this last and an ensemble of forecasted hydrographs. A possible approach could be to evaluate the correlation (or other skill estimator like the Root Mean Square Error or the Nash-Sutcliffe efficiency coefficient) at each time step $(t)$ and for different lag times $(\tau)$, using as forecast value:

$Q_{\mathrm{f}}^{\tau}(t)=\sum_{i=1}^{n} p_{i} \cdot q_{i}^{\tau}(t)$

where $Q_{\mathrm{f}}^{\tau}(t)$ is the weighted forecasted flow value to compare with reference flow, $p_{i}$ is the weight of the discharge scenario $q_{i}^{\tau}(t), n$ is the number of scenarios.

This approach leads to the problem of evaluating the weight $p_{i}$ of the various ensemble members. PhaSt generates ensemble members that are equi-probable (Metta et al., 2009), as a consequence the discharge scenarios are equiprobable. Basing on Eq. (7), we simply compare the mean flow of the $\mathrm{n}$ discharge scenarios with the reference flow at each time step. All this leads to a reductive interpretation of probabilistic forecasts, because the forecaster could only be interested in the most dangerous scenarios based on the context and on the degree of risk that he can or wants to assume.

One of the main quantities of interest when it is necessary to forecast or simulate the streamflow due to a severe rainfall event, is the peak flow. It can be defined in terms of the value $\left(Q_{\mathrm{p}}\right)$ and time of the peak $\left(t_{\mathrm{p}}\right)$. It is crucial because it allows us to know if the occurring event can cause a flood and if it is critical for a certain basin.

On the basis of these considerations we decided to use the following technique of verification.

A preliminary analysis of the reference hydrograph is carried out in order to identify the peak flow in terms of $Q_{\mathrm{p}}$ and $t_{\mathrm{p}}$. We then uppose we are in the past $t_{\mathrm{p}}$ of a certain lag time $\tau$. At this stage the questions are two: (1) how do we define $\tau$ and what is its maximum value? (2) What information can the hydrological nowcasting framework give to the forecaster at the instant $t_{\mathrm{p}}-\tau$ ?

Referring to Fig. 3 we defined $\tau_{\max }$ as follows:

$\tau_{\max }=t_{\mathrm{nc}}+t_{\mathrm{b}}$

where $t_{\mathrm{nc}}$ is the duration for which the nowcasting system produces the rainfall ensemble (in general no more than 2$3 \mathrm{~h}) . t_{\mathrm{b}}$ is the characteristic lag time of the basin, and it is 


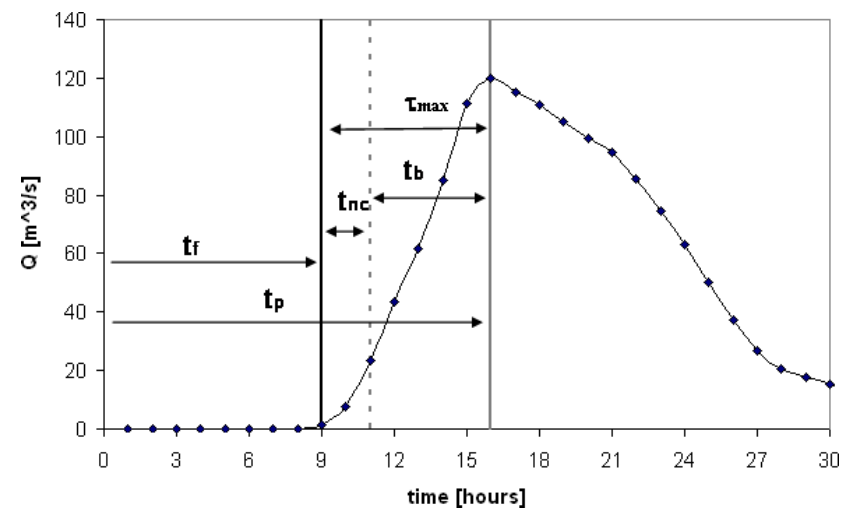

Fig. 3. Reference schematization for the verification methodology. $t_{\mathrm{f}}$ is the time of forecast, $t_{\mathrm{p}}$ is the peak time, $t_{\mathrm{nc}}$ is the nowcasting window time, $t_{\mathrm{b}}$ is the basin characteristic lag time, $\tau_{\max }$ is the theoretical maximum lag time for discharge forecast.

usually defined as the temporal distance between the centre of mass of the hydrograph and the centre of mass of the mean hyetograph.

In practice $t_{\mathrm{b}}$ varies from event to event but it can be considered to be almost constant. The Soil Conservation Service empirically deducted that the ratio between the concentration time and lag time is about 0.6 (Maidment, 1992; Mishra and Singh, 2003).

$\tau_{\max }$ defines the maximum time window before the peak (or in general before a certain time) for which we can expect a reliable forecast, it can be considered a physical boundary. If the nowcasting technique produces a perfect forecast during $t_{\mathrm{nc}}$, we can reproduce quite well the reference hydrograph for the following $t_{\mathrm{b}}$ window time. Beyond this time, the basin response is influenced too much by the rainfall that occurs after $t_{\mathrm{p}}-t_{\mathrm{b}}$.

Since $t_{\mathrm{nc}}$ can be in general two or three hours, it is not of great interest analyzing what happens when $\tau<t_{\mathrm{nc}}$ because a little new information is introduced compared to using only the observed rainfall fields.

In the presented analysis $\tau$ varies in the range $t_{\mathrm{nc}} \leq \tau \leq$ $t_{\mathrm{nc}}+t_{\mathrm{b}}$.

It can easily be deduced that $\tau_{\max }$ depends on the basin characteristics; it can theoretically be about $4-6 \mathrm{~h}$ for basins of $200-400 \mathrm{~km}^{2}$, reducing to $2-3 \mathrm{~h}$ for very small basins $\left(\right.$ area $<100 \mathrm{~km}^{2}$ ) where $t_{\mathrm{nc}} \sim t_{\mathrm{nc}}+t_{\mathrm{b}}$.

We carried out two types of experiments depending on the drainage area of the considered basins. The objective is always to forecast the peak flow with the maximum possible anticipation.

For basins with an area greater than $150 \mathrm{~km}^{2}$, the behavior of the hydrological nowcasting chain is investigated varying $\tau$ between $t_{\mathrm{nc}}$ and $t_{\mathrm{nc}}+t_{\mathrm{b}}$.

For basins with area lower than $150 \mathrm{~km}^{2} \tau$ is imposed to the value of $t_{\mathrm{nc}}+1 \mathrm{~h}$. In these cases the $t_{\mathrm{b}}$ is generally lower than $2 \mathrm{~h}$.
In both cases the steps to evaluate the performance of the nowcasting chain for a fixed $\tau$ are the following:

1. Since the peak flow is the target occurrence to predict, for each basin the peak flow time $t_{\mathrm{p}}$ is individuated.

2. For each basin the forecast time is individuated as $t_{\mathrm{f}}=$ $t_{\mathrm{p}}-\tau$ (one for each basin)

3. Supposing to effectuate the forecast at the time $t_{\mathrm{f}}$, the performance of the hydrological nowcasting framework is carried out in terms of peak flows and peak times.

The peak flows verification is achieved comparing the peak flow of the reference hydrograph (named $Q_{\mathrm{pr}}$ ) with the peak flows deriving from the forecast $\left(Q_{\mathrm{pf}}\right)$. When $Q_{\mathrm{pr}}$ lies in the range between maximum and minimum forecasted peak flows ( $Q_{\mathrm{pfMax}}$ and $Q_{\mathrm{pfMin}}$ ), we consider that the hydrological nowcasting framework makes a good forecast. A certain level of uncertainty is associated with the forecast discharge scenarios and it could be measured for example with the variance of the peak flows.

The peak time corresponding to $Q_{\mathrm{pr}}$ is then compared with the peak times of the forecasted discharge scenarios.

\section{Application}

The methodology has been applied to a set of events which caused evident ground effects in the Liguria Region. The events have been chosen firstly taking into account the availability of reliable radar data. We checked that the radar system was correctly functioning and that the rainfall estimation was unaffected by bias or evident errors. To reach this goal, we applied the methodology of radar-gauge comparison illustrated in Silvestro et al. (2009). It is true that the radar rainfall fields in this work are corrected with rain gauge data, but we wanted to be sure to start from a good quantitative rainfall estimation. The adjustment algorithm is in fact applied only to the observed part of the rainfall scenarios, because in a real time application the rain gauge data for the nowcasted part of scenario are obviously not available. Moreover we carried out a further selection, individuating those events that caused significant streamflow. A streamflow threshold has been defined discarding, for each event, the basins where both the peak flow of reference hydrograph and the maximum of the peaks of the discharge scenarios are under the threshold.

Since the objective is testing the application in an operational context, two facts must be highlighted. The first is that the number of scenarios is fixed equal to $20, N_{\mathrm{e}}=20$; based on their experience, authors think that this is a good compromise between the correct representation of the variability of the possible scenarios and a reduced computational time. The system must in fact produce results extremely quickly (order of magnitude of in a matter of minutes). 
Table 2. Test events characteristics. The average accumulated rainfall is calculated as the mean of the accumulated rainfall over the entire event for every rain gauge. The maximum accumulated rainfall is the maximum accumulated rainfall measured by a rain gauge. $\mathrm{N}$. gauges is the number of rain gauges that measured a precipitation greater than $2 \mathrm{~mm}$ over the event.

\begin{tabular}{lrrrr}
\hline Date & $\begin{array}{r}\text { Duration } \\
(\mathrm{h})\end{array}$ & $\begin{array}{r}\text { Average } \\
(\mathrm{mm})\end{array}$ & $\begin{array}{r}\text { Maximum } \\
(\mathrm{mm})\end{array}$ & $\begin{array}{r}\text { N. } \\
\text { gauges }\end{array}$ \\
\hline 16 Aug 2006 & 8 & 50 & 337 & 40 \\
14 Sep 2006 & 24 & 138 & 290 & 106 \\
21 Oct 2009 & 18 & 120 & 243 & 73 \\
30 Mar 2010 & 3 & 15 & 70 & 20 \\
\hline
\end{tabular}

The second is that the last observed rainfall field (one hour accumulation) can not be estimated with the complete version of the radar-gauge adjustment algorithm. Also, the modern telemetric rain-gauge networks have a certain delay time in elaborating and sending the data to the collection centres. Moreover, the procedures to carry out quality verification and to render the data available in a database for hydrometeorological routines need more time.

Based on our experience, we consider that one hour is a reasonable time delay $\left(t_{\mathrm{d}}\right)$ to have a high percentage of rain gauges with updated data in a real-time system. In practice we assume that only radar data are available from the time $t_{\mathrm{f}}-t_{\mathrm{d}}$ to $t_{\mathrm{f}}$ in order to build the observed part of the event (see Fig. 2).

In Table 2 the four selected events are reported together with their main characteristics. There were two very intense events (16 August 2006 and 14 September 2006) characterized by very high rainfall intensities, one autumnal event (21 October 2009), less intense and with stratiform attributes during which some organized structures with relative high intensities occurred, and a typical thunderstorm with reduced duration and presence of localized intense cells (30 March 2010).

The basin characteristic time lag is estimated using the formulation of Soil Consevartion Service (Maidment, 1992):

$t_{\mathrm{b}}=0.6 \times t_{\mathrm{c}}$

where $t_{\mathrm{c}}$ is the concentration time, calculated with a formulation that produces reasonable results for the basins which are placed in the Ligurian territory, and thus with definite morphologic characteristics like slope, range of area, and main channel length. The formulation is very simple and depends only on the drainage area:

$t_{\mathrm{c}}=0.27 \times \sqrt{A}+0.25$

where $A$ is the basin area in $\mathrm{km}^{2}, t_{\mathrm{c}}$ the concentration time in hours.
Table 3. Characteristics of the considered catchments with an area greater than $150 \mathrm{~km}^{2} . t_{\mathrm{c}}$ is the basin concentration time and $t_{\mathrm{b}}$ is the basin lag time.

\begin{tabular}{lrrr}
\hline Basin & $\begin{array}{r}\text { Area } \\
\left(\mathrm{km}^{2}\right)\end{array}$ & $\begin{array}{r}t_{\mathrm{c}} \\
(\mathrm{h})\end{array}$ & $\begin{array}{r}t_{\mathrm{b}} \\
(\mathrm{h})\end{array}$ \\
\hline Bormida & 243 & 4.4 & 2.7 \\
Entella & 364 & 5.4 & 3.2 \\
Scrivia & 282 & 4.8 & 2.9 \\
\hline
\end{tabular}

\subsection{Catchments with area $>150 \mathrm{~km}^{2}$}

The analysis of basins with an area greater than $150 \mathrm{~km}^{2}$ is carried out on the catchments where not negligible streamflow occurred during the considered events. Three basins for three different events have been individuated with an extension that allows us to investigate a reasonable variation of $\tau$ (3-4h). The main characteristics of the catchments are reported in Table 3 and their location is shown in Fig. 1.

Multi plots which are shown in Figs. 4 to 6 report the results for the considered catchments. Time is shown on $\mathrm{x}$-axis while y reports the discharge, the vertical black line indicates the time of forecast, the vertical grey line indicates the end of rainfall derived by the nowcasting procedure. The graphs report the reference hydrograph, the run obtained using only the observed rainfall and the forecasted discharge scenarios. For all three cases we considered $t_{\mathrm{nc}}=2 \mathrm{~h}$ and $t_{\mathrm{b}}=3 \mathrm{~h}$, and the forecast effectuated at four different instants $\left(t_{\mathrm{f}}\right)$ are reported. They vary between $5 \mathrm{~h}$ to $2 \mathrm{~h}$ before the peak flow.

The results are positive although not excellent. The graphs show a good information content, particularly in the case of the Entella river. The reference hydrographs belong to the forecasted scenarios for values of $\tau$ between 2 and $4 \mathrm{~h}$. The reference peak flow remains between minimum and maximum forecasted peak flows.

For $\tau=5 \mathrm{~h}$ the results are scarce. In the cases of the Scrivia and Bormida rivers, the discharge scenarios are evidently better in respect to the discharge simulation obtained using only the observed rainfall as input into rainfall-runoff model and they are closer to the reference hydrograph, but the forecast is underestimated.

As demonstrated by other authors (Berenguer et al., 2005; Vivoni et al., 2006), accuracy in predicting the rainfall fields becomes more crucial the more we move forward with respect to the time $\left(t_{\mathrm{f}}=t_{\mathrm{p}}-\tau\right)$ of the last available observation. When the volume of precipitation that falls over the basin during the time $t_{\mathrm{nc}}$ is reproduced with good accuracy, the reference hydrograph can be reproduced with reduced errors from $t_{\mathrm{f}}$ to $t_{\mathrm{f}}+\tau$. There are two main reasons that lead to a bad rainfall forecast: (i) the motion field is not correctly estimated, and the rainfall is badly localized (ii) the rainfall volume over the basin is strongly biased because of the growth and decay of precipitation cells. 

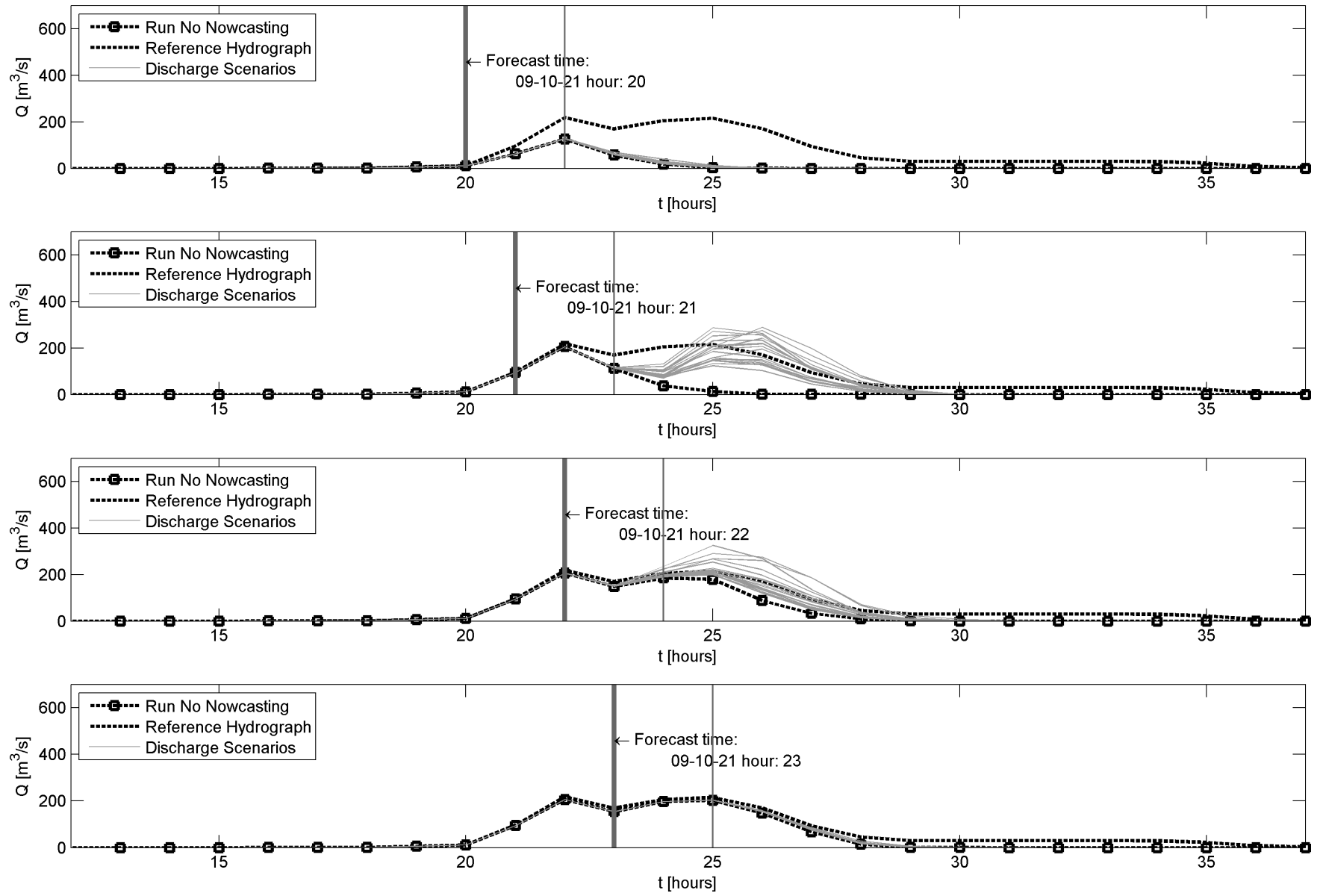

Fig. 4. Results of hydrological nowcasting framework for the Entella Basin closed at Panesi (Area $=364 \mathrm{~km}^{2}$ ). The event on 21 Oct 2009 is shown. The thick grey vertical line represents the time of the last available observed field for each nowcasted scenario. The thin grey vertical line represents the end of nowcasting. The Run No Nowcasting is the discharge obtained feeding the rainfall-runoff model with observed rainfall only.

This last problem is quite impossible to deal with when a common nowcasting algorithm is used; this is because they do not have a dynamic description of atmosphere so they can't create new precipitation. They do not correctly describe the process of growth and decay of new rainfall structures. This is valid also for PhaSt, since it is based on the hypothesis of the advection of the total volume of precipitation detected in the observed rainfall fields. PhaSt only allows the cells of precipitation to be combined to create a greater and more intense structure. The probabilistic approach allows us to generate a different motion field for each ensemble member; this increases the probability of estimating the correct direction of the perturbation and is an attempt to overcome the problem of the bad rainfall localization.

All this can be easily confirmed by looking at Fig. 7, the case of the Entella basin event on 21 October 2010, where the accumulated rainfall on the basin is plotted for every forecast time. The plotted graphs are derived by the rainfall inputs used to produce the results in Fig. 4. Looking at the two figures at the same time, it is evident that the bad performance in forecasting the discharge for $t f=20: 00$ (Fig. 4) are due to a bad performance in forecasting the rainfall on the basin. All the rainfall scenarios are underestimated in respect to the reference hyetograph (Fig. 7).

Another interesting result to point out is the case of the Scrivia basin for $\tau=2 \mathrm{~h}, t_{\mathrm{f}}$ equal to 16 August 2006, 08:00 (Fig. 5). The forecast time is really next to the peak time of reference discharge (that occurred at 10:00), but during the hour before the forecast time the rainfall was negligible, and as a consequence, PhaSt does not allow us to produce a reliable rainfall forecast. The result is that the system furnishes a discharge forecast that is worse for $\tau=2 \mathrm{~h}$ than for the cases of $\tau=3 \mathrm{~h}$ and $\tau=4 \mathrm{~h}$.

The probabilistic approach accounts for the uncertainty of the nowcasted rainfall estimation and it helps to improve the performance of the forecast system but, because of the limits of the nowcasting algorithm, it doesn't manage to produce good results in all the situations. 

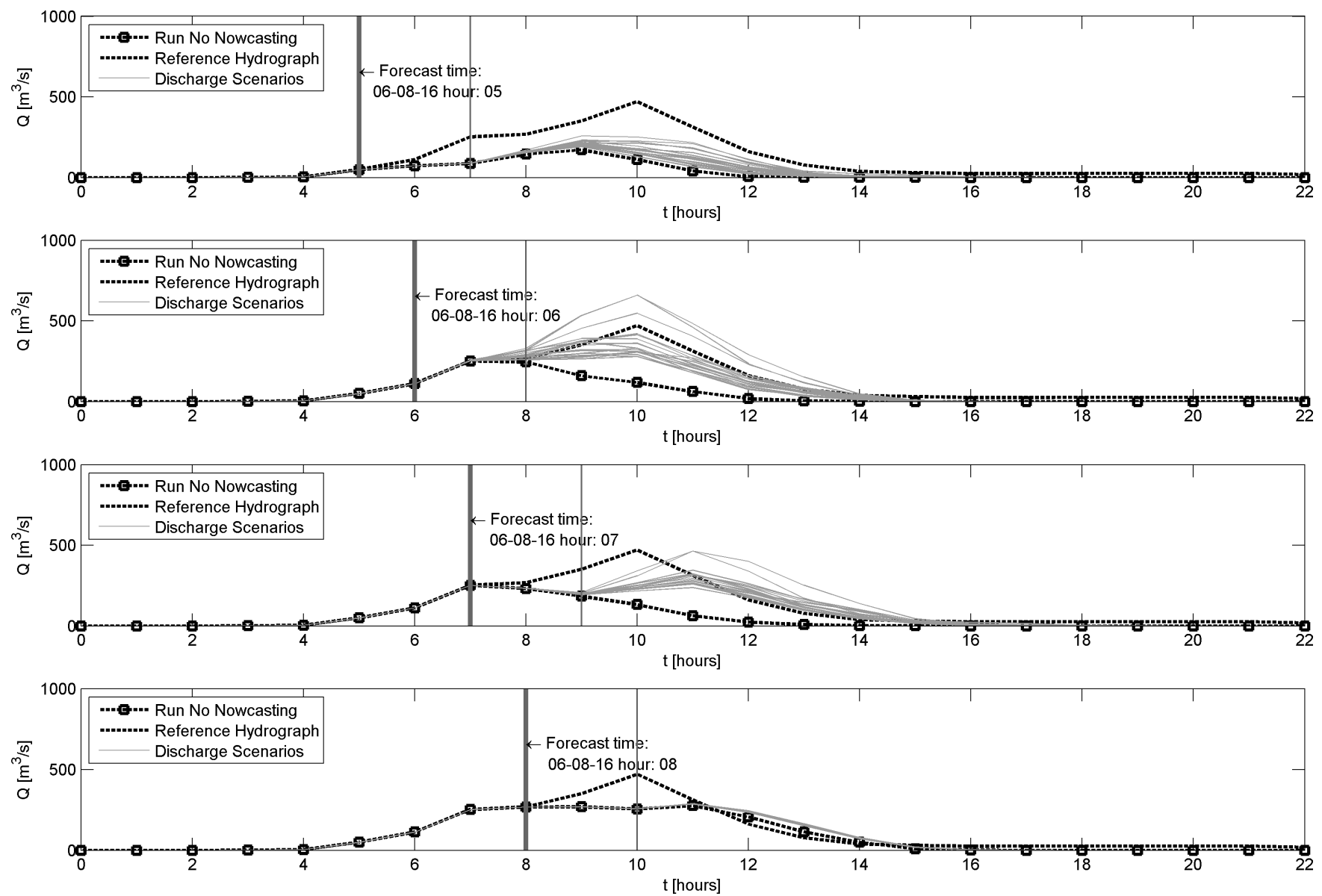

Fig. 5. Results of hydrological nowcasting framework for the Scrivia basin closed at Mereta (Area $=282 \mathrm{~km}^{2}$ ). The event on 16 Aug 2006 is shown. The thick grey vertical line represents the time of the last available observed field for each nowcasted scenario. The thin grey vertical line represents the end of nowcasting. The Run No Nowcasting is the discharge obtained feeding the rainfall-runoff model with observed rainfall only.

\subsection{Catchments with area $\leq 150 \mathrm{~km}^{2}$}

Analysis was done on all of the Ligurian basins hit by the considered events. We used the results for those basins where the peak flow of the reference hydrograph and the maximum of the peak flows of the discharge scenarios were both greater than a threshold $\left(Q_{\mathrm{TH}}=10 \mathrm{~m}^{3} \mathrm{~s}^{-1}\right)$. In Table 4 the number of considered basins for each event are reported, they have drainage area in the range $20-150 \mathrm{~km}^{2}$.

Figure 8 shows synthetically the results in terms of peak flows. X-axis reports the progressive number of basin/event, the results for all the events, and all the involved basins are reported. On y-axis the forecasted peak flows $\left(Q_{\mathrm{pf}}\right)$ are plotted using the box plot technique after they are normalized with the peak flow of the reference hydrograph $\left(Q_{\mathrm{pr}}\right)$. The black dots correspond to $Q_{\mathrm{pf}}=Q_{\mathrm{pr}}$, while the box plots whiskers indicate the maximum and minimum forecasted peak flows. The red line indicates the mean value and the box indicates the $25 \%$ and $75 \%$ quantiles.
Table 4. Number of involved modelled basins for each event. Basins where both the peak flow of the reference hydrograph and the maximum of the peaks of the discharge scenarios are under a fixed threshold have been discarded.

\begin{tabular}{ll}
\hline Date & Number of basins \\
\hline 16 Aug 2006 & 11 \\
14 Sep 2006 & 15 \\
21 Oct 2009 & 4 \\
30 Mar 2010 & 6 \\
\hline
\end{tabular}

This kind of graph allows us to show the results at a glance.

In many cases, the $Q_{\mathrm{pr}}$ values remain in the range individuated by maximum and minimum peak flows and sometimes between the $25 \%$ and $75 \%$ quantiles, but there are also various cases where the hydrological nowcasting system fails. It is evident that in various cases the level of uncertainty is quite high, with a spread of $Q_{\mathrm{pf}}$ in the range [ $Q_{\mathrm{pr}} / 4 / 4 Q_{\mathrm{pr}}$ ], this is particularly stressed for very small basins where small 

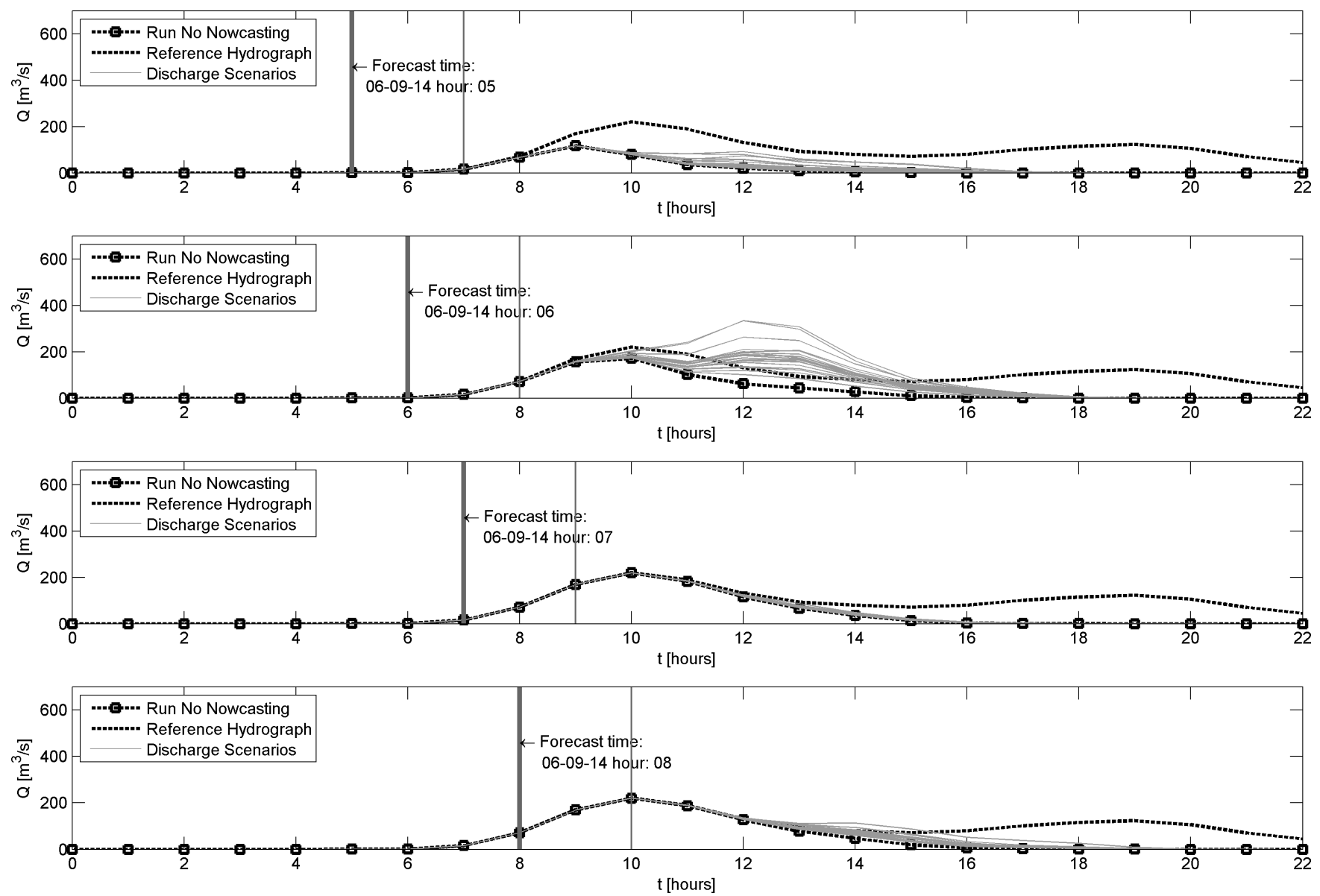

Fig. 6. Results of hydrological nowcasting framework for the Bormida basin closed at Valle Acna $\left(\right.$ Area $\left.=243 \mathrm{~km}^{2}\right)$. The event on 14 Sep 2006 is shown. The thick grey vertical line represents the time of the last available observed field for each nowcasted scenario. The thin grey vertical line represents the end of nowcasting. The Run No Nowcasting is the discharge obtained feeding the rainfall-runoff model with observed rainfall only.

differences of motion fields can track very different amounts of precipitation on the watershed.

We built a contingency table for the evaluation of the performance considering the following definitions:

1. False Alarms (FA): the percentage of cases where $Q_{\mathrm{pr}}$ is lower than the minimum $Q_{\mathrm{pf}}$.

2. Missed Alarms (MA): the percentage of cases where $Q_{\mathrm{pr}}$ is greater than the maximum $Q_{\mathrm{pf}}$.

3. Good forecasts (GF): the percentage of cases where $Q_{\mathrm{pr}}$ is between the maximum and the minimum $Q_{\mathrm{pf}}$.

We can then define:

$\mathrm{POD}=\frac{\mathrm{GF}}{\mathrm{GF}+\mathrm{FA}}$

$\mathrm{FAR}=\frac{\mathrm{MA}}{\mathrm{GF}+\mathrm{FA}}$

$$
\begin{aligned}
& \mathrm{CSI}=\frac{\mathrm{GF}}{\mathrm{GF}+\mathrm{MA}+\mathrm{FA}} \\
& \mathrm{BIAS}=\frac{\mathrm{GF}+\mathrm{MA}}{\mathrm{GF}+\mathrm{FA}}
\end{aligned}
$$

The results are reported in Table 5. Half of the events are well predicted by the system $(\mathrm{GF}=0.5)$ and this is not a bad result in our opinion; there are very few FA but a considerable number of MA (44\%).

MA are in part due to a completely wrong estimation of the mean direction of motion field in all the nowcasted rainfall scenarios, but mainly they are caused by the impossibility of the rainfall nowcasting algorithm to generate new cells of precipitation starting from observations with a scarce amount of rainfall.

In Fig. 9 the results in terms of the time of the peak flow are shown. X-axis reports the progressive number of basin/event, $y$-axis reports the difference between the peak time of the forecasted hydrograph and the peak time of the reference hydrograph. For every $x$ value, the dot is the reference 

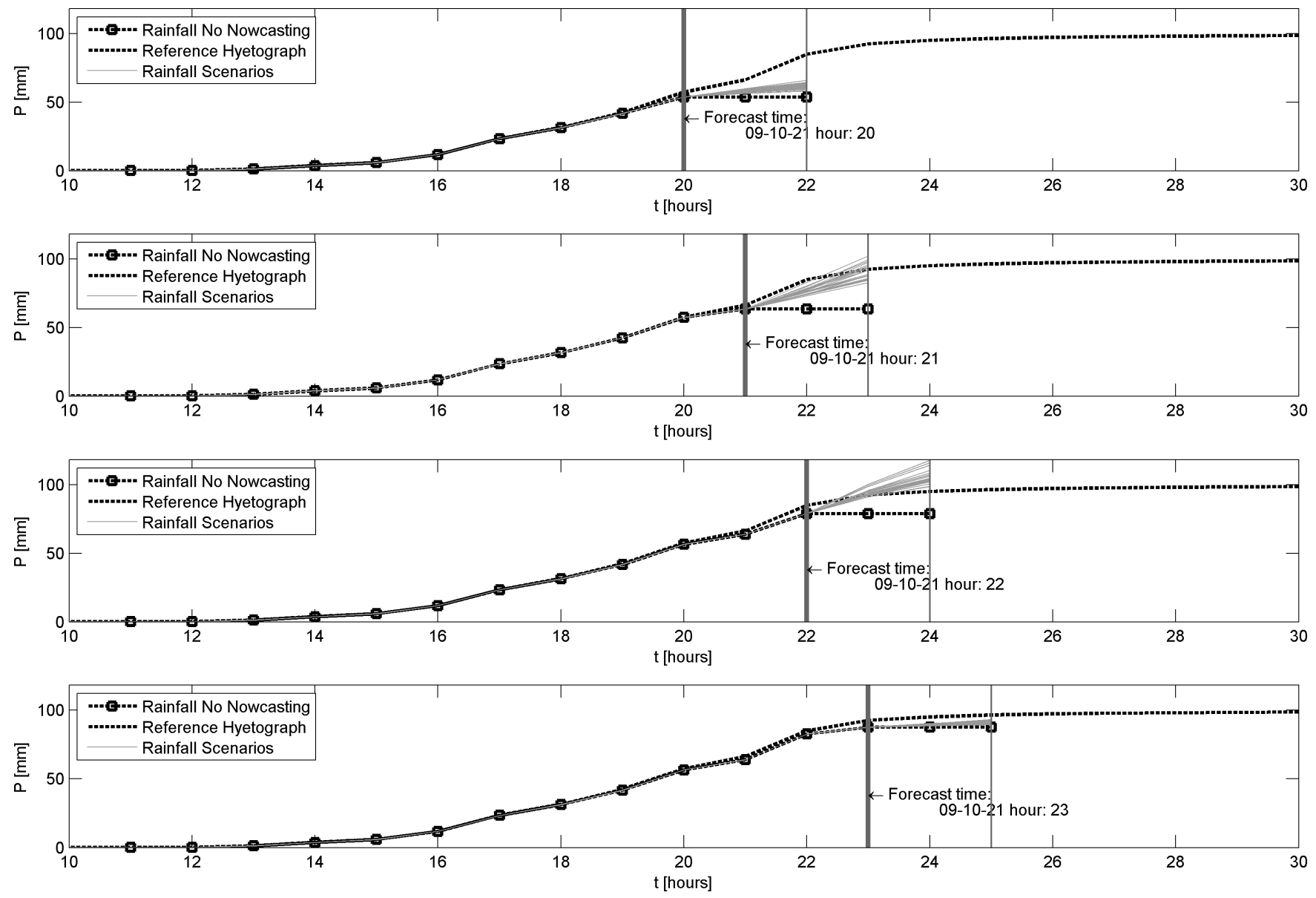

Fig. 7. Accumulated precipitation at basin scale for the case of the Entella Basin closed at Panesi (Area $\left.=364 \mathrm{~km}^{2}\right)$. Event on 21 Oct 2009. Referring to Fig. 4, the close relationship between good performance of nowcasting algorithm and the good results of the framework in terms of discharge can be highlighted.

Table 5. Score values for basins with area $\leq 150 \mathrm{~km}^{2}$. FA are the false alarms, MA are the missed alarms, GF are the good forecasts.

\begin{tabular}{lrr}
\hline Score & Value $(-)$ & Value $(\%)$ \\
\hline FA & 0.056 & 5.6 \\
MA & 0.444 & 44.4 \\
GF & 0.5 & 50 \\
POD & 0.9 & 90 \\
FAR & 0.47 & 47 \\
CSI & 0.5 & 50 \\
BIAS & 1.7 & - \\
\hline
\end{tabular}

hydrograph peak time, the triangles are the maximum and the minimum peak times of the discharge ensemble members, and the $x$ is the mean of the peak times of the discharge ensemble members.

The number of GF that respect the condition of having an absolute error of the mean peak time with respect to the reference peak time that is lower or equal to $1 \mathrm{~h}$ are used to estimate a new quantity: GFT. It represents the good forecast in terms of both peak flows and peak times. GFT $=36 \%$.

In order to evaluate the performance of the rainfall-runoff model fed with observed rainfall, in Table 6, the comparison between the values of the peak flows of the reference hydrographs and the peak flows derived by the observations through stream level gauges is illustrated. These measures are available for a reduced number of basins only.

\section{Conclusions}

In this work we present the application in an operational context of a probabilistic hydrological nowcasting framework. It is a system that uses a probabilistic approach to exploit the rainfall fields derived from meteorological radar as forcing of a nowcasting algorithm and uses its output to feed a rainfallrunoff model. The methodology accounts for the uncertainties associated with the outputs of a nowcasting technique and propagates them in the rainfall-runoff model, generating 
Table 6. Comparison between the values of the discharge peaks of the reference hydrographs $\left(Q_{\mathrm{pr}}\right)$ and the peaks derived by the observations through level gauges $\left(Q_{\mathrm{po}}\right)$. These measurements are available for a reduced number of basins only.

\begin{tabular}{llrlrr}
\hline Basin & Outlet & $\begin{array}{r}\text { Area } \\
\left(\mathrm{km}^{2}\right)\end{array}$ & Date & $\begin{array}{r}Q_{\mathrm{po}} \\
\left(\mathrm{m}^{3} \mathrm{~s}^{-1}\right)\end{array}$ & $\begin{array}{r}Q_{\mathrm{pr}} \\
\left(\mathrm{m}^{3} \mathrm{~s}^{-1}\right)\end{array}$ \\
\hline Entella & Panesi & 364 & 21 Oct 2009 & 199 & 206 \\
Orba & Tiglieto & 72 & 16 Aug 2006 & 398 & 350 \\
& & & 14 Sep 2006 & 352 & 385 \\
Bormida & Murialdo & 130 & 14 Sep 2006 & 110 & 150 \\
\hline
\end{tabular}

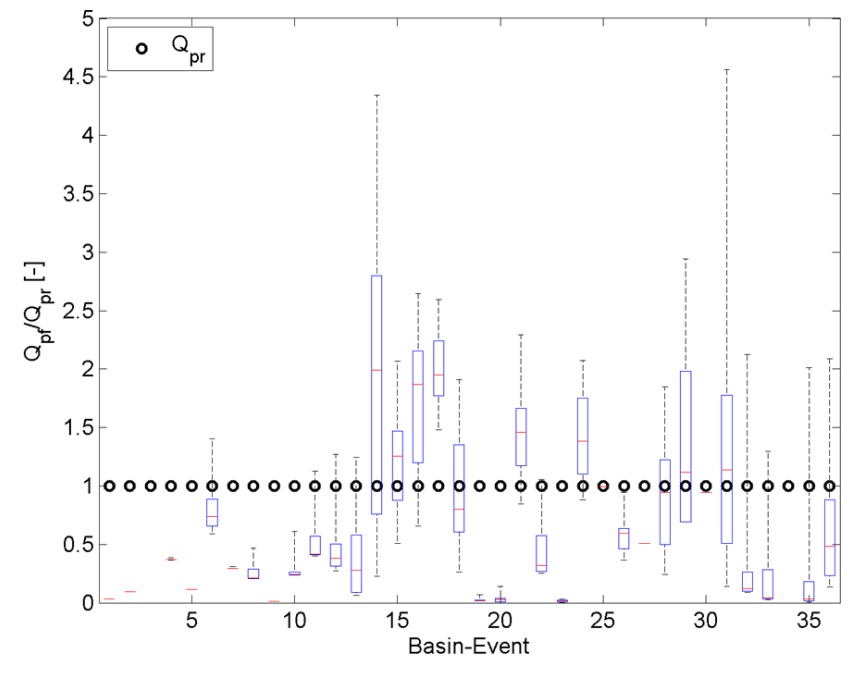

Fig. 8. Results of hydrological nowcasting framework for basins with area $\leq 150 \mathrm{~km}^{2}$ in terms of peak flow with box plot representation. The black dots are the $Q_{\mathrm{pr}}$ (peaks of reference hydrographs). The box plots' whiskers indicate the maximum and minimum peak flows, the red line indicates the mean value and the box indicates the $25 \%$ and $75 \%$ quantiles.

an ensemble of forecasted discharge simulations, instead of the more commonly used deterministic scenario. It is based on the following procedures: (i) an algorithm for radarrain gauge measurement combination, (ii) an algorithm for probabilistic nowcasting (PhaSt) and (iii) a semi-distributed rainfall-runoff model (DRiFt).

The presented framework is an attempt to provide the forecasters with a tool that could be used during the phase of monitoring and nowcasting of severe rainfall events. We assume we are in a warning condition because an intense rainfall even is occurring. Based on proper meteo-hydrological procedures, a hypothetical civil protection system issued an alert on a large region. In this condition the opportunity for producing a hydrological forecast on a time horizon of threesix hours could be very useful, particularly when we deal with small and medium size basins.

The hydrological nowcasting system has been applied in the Italian Region of Liguria where the greater part of the

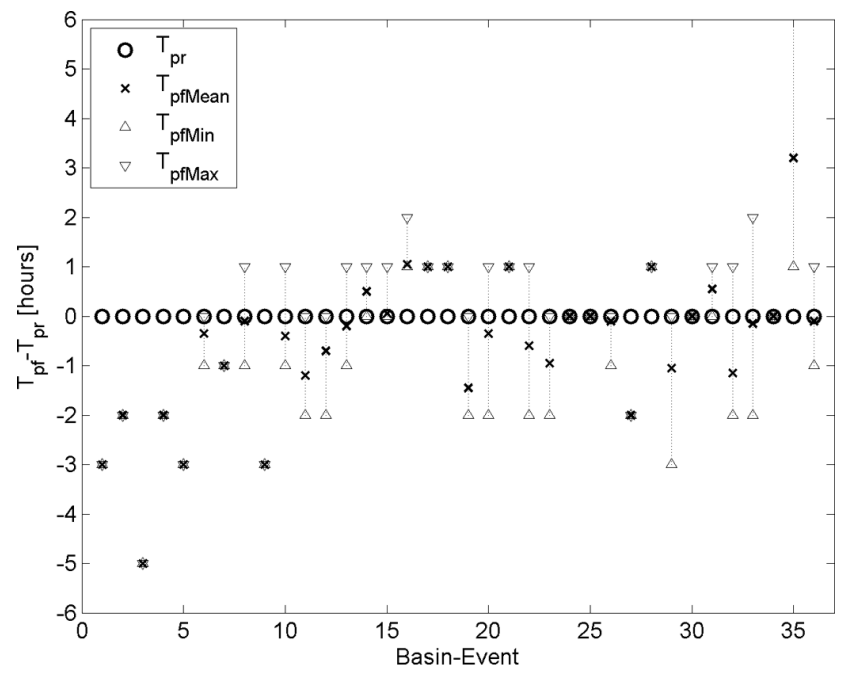

Fig. 9. Results of hydrological nowcasting framework for basin with area $\leq 150 \mathrm{~km}^{2}$ in terms of time of the peak flow. The dots are the reference hydrograph peak time, the triangles are the maximum and the minimum peak times of the discharge ensemble, the $x$ is the mean of the peak times of the discharge ensemble.

catchments have a drainage area of less than $1000 \mathrm{~km}^{2}$. The adopted verification methodology is built having as a target the forecast of the peak flow with the maximum possible anticipation.

The investigation about the effects of the uncertainties related to the rainfall-runoff model parameterization and initialization has not been carried out. Moreover the results in Table 6 show that the model is quite well calibrated in the context of application.

The application of the system to a selected sample of events for which the reliability of observed rainfall estimation was verified, allowed us to neglect a discussion about its uncertainty. Uncertainties related to the rainfall-runoff model and to the observed rainfall estimation (Germann et al., 2009) are crucial issues but they are not the main objective of this work. A detailed analysis of these topics is carried out in Carpenter and Georgakakos (2006b) and in Zappa et al. (2011). 
The results show that, in some situations, the benefit of the probabilistic approach is evident. The forecast must be used with caution and prudence and needs to be interpreted by an expert user because it is characterized by a high uncertainty level. The impossibility to completely reproduce the processes related to the growth and decay of new cells, can lead to a wrong prediction. Therefore the forecaster should be prepared to recognize the weather conditions that can be well described by the rainfall nowcasting methodology (PhaSt). These conditions mainly depend on the type of the occurring event.

Reliable, quantitative forecasting of precipitation in a time horizon of $6-8 \mathrm{~h}$ always remains to be the crucial point to adequately nowcast flash floods; the probabilistic approach partially covers the lack of knowledge about future rainfall but is inadequate in a significant percentage of situations when strong orographic and/or convective effects are present. These latter events cannot be forecasted based on the most recent observed rainfall fields (by weather radar and other measurement systems).

A great improvement to the framework performance could be achieved by using more sophisticated nowcasting systems that account for the atmospheric dynamic and its state and that are able to predict new precipitation structures. These systems should maintain, in our opinion, a probabilistic approach.

This is a very hard issue to pursue; it cannot be reached by using radar information only as the available input. The scientific community is committed to resolving it.

Currently methodologies, like the one presented in this work, can help to account for the uncertainties associated with the process of generation of the nowcasted rainfall fields and to propagate them for predicting streamflow. They can be useful if used by an expert forecaster, but they cannot be employed without an adequate and careful interpretation of the results.

Acknowledgements. This work is supported by the Italian Civil Protection Department and by the Italian Region of Liguria. We acknowledge the Liguria Region for providing us with the data from the regional meteorological observation network and from the weather radar on Settepani mountain. We are very grateful to the meteorologists and the hydrologists of the Meteo-Hydrologic Centre of Liguria Region (CMIRL) for the many useful discussions we had. We are also grateful to the anonymous referees for their helpful reviews and to Mike Whalley for his suggestions in reviewing the quality of the writing.

Edited by: N. Kerle

Reviewed by: two anonymous referees

\section{References}

Achleitner, S., Fach, S., Einfalt, T., and Rauch, W.: Nowcasting of rainfall and of combined sewage flow in urban drainage systems, 11th International Conference on Urban Drainage, Edinburgh, Scotland, UK, Proceedings, 2008.

Berenguer, M., Corral, C., Sanchez-Diesma, R., and SempereTorres, D.: Hydrological validation of a radar-based nowcasting technique, J. Hydrometeorol., 6, 532-549, 2005.

Boni, G., Ferraris, L., Giannoni, F., Roth, G., and Rudari, R.: Flood probability analysis for un-gauged watersheds by means of a simple distributed hydrologic model, Adv. Water Resour., 30, 2135 2144, 2007.

Borga, M.: Accuracy of radar rainfall estimates for streamflow simulation, J. Hydrol., 267, 26-39, 2002.

Carpenter, T. M. and Georgakakos, K. P.: Discretization scale dependencies of the ensemble flow range versus catchment area relationship in distributed hydrologic modeling, J. Hydrol., 328, 242-247, 2006a.

Carpenter, T. M. and Georgakakos, K. P.: Intercomparison of lumped versus distributed hydrologic model ensemble simulations on operational forecast scales, J. Hydrol., 329, 174-185, $2006 b$.

Cloke, H. L. and Pappenberger, F.: Ensemble Flood Forecasting: a review, J. Hydrol., 375, 613-626, 2009.

Creutin, J. D., Borga, M., Lutoff, C., Scolobig, A., Ruin, I., and Creton-Cazanave, L.: Catchment dynamics and social response during flash floods: The potential of radar rainfall monitoring for warning procedures, Meteorol. Appl., 16, 115-125, doi:10.1002/met.128, 2009.

Deidda, R., Benzi, R., and Siccardi, F.: Multifractal modeling of anomalous scaling laws in rainfall, Water Resour. Res., 35, 1853-1867, 1999.

Droegemeier, K. K., Smith, J. D., Businger, S., Doswell III, C., Doyle, J., Duffy, C., Foufoula-Georgiou, E., Graziano, T., James, L. D., Krajewski, V., LeMone, M., Lettenmaier, D., Mass, C., Pielke Sr., R., Rutledge, S., Ray, P., Schaake, J., and Zipser, E.: Hydrological Aspects of Weather Prediction and Flood Warnings: Report of the Ninth Prospectus Development Team of the US Weather Research Program, B. Am. Meteorol. Soc., 81, 2665-2680, 2000.

Ebert, E. E., Wilson, L. J., Brown, B. G., Nurmi, P., Brooks, H. E., Bally, J., and Jaeneke, M.: Verification of Nowcasts from the WWRP Sydney 2000 Forecast Demonstration Project, Weather Forecast., 19, 73-96, 2004.

Gabella, M., Joss, J., Perona, G., and Galli, G.: Accuracy of rainfall estimates by two radars in the same Alpine environment using gauge adjustment, J. Geophys. Res., 106, 5139-5150, 2001.

Gabellani, S., Silvestro, F., Rudari, R., and Boni, G.: General calibration methodology for a combined Horton-SCS infiltration scheme in flash flood modeling, Nat. Hazards Earth Syst. Sci., 8, 1317-1327, doi:10.5194/nhess-8-1317-2008, 2008.

Germann, U. and Zawadzki, I. : Scale-dependence of the predictability of precipitation from continental radar images, Part I: Description of the methodology, Mon. Weather Rev., 130, 28592873, 2002.

Germann, U., Berenguer, M., Sempere-Torres, D., and Zappa M.: REAL: Ensemble radar precipitation estimation for hydrology in a mountainous region, Q. J. Roy. Meteor. Soc., 135, 445-456, 2009. 
Giannoni, F., Roth., G., and Rudari, R.: A Semi - Distributed Rainfall - Runoff Model Based on a Geomorphologic Approach, Phys. Chem. Earth, 25, 665-671, 2000.

Giannoni, F., Roth., G., and Rudari, R. : Can the behaviour of different basins be described by the same model_s parameter set?, A geomorphologic framework, Phys. Chem. Earth, 28, 289-295, 2003.

Golding, B. W.: Nimrod: A system for generating automated very short range forecasts, Meteor. Appl., 5, 1-16, 1998.

Keenan, T., Joe, P., Wilson, J. W., Collier, C., Golding, B., Burgess, D., May, P., Pierce, C., Bally, J., Crook, A., Seed, A., Sills, D., Berry, L., Potts, R., Bell, I., Fox, N., Ebert, E., Ehlts, M., O'Loughlin, K., Webb, R., Carbone, R., Browning, K., Roberts, R., and Mueller, C.: The sydney 2000 world weather research programme forecast demonstration project overview and current status, Technical report, American Meteorological Society, 2003.

Kim, S., Tachikawa, Y., Sayama, T. and Takara, K.: Ensemble flood forecasting with stochastic radar image extrapolation and a distributed hydrological model. Hydrological Processes, 23, 597$611,2009$.

Koistinen, J. and Puhakka, T.: An improved spatial gauge-radar adjustment technique, Proc. 20th Conf. on Radar Met., AMS, 179$186,1981$.

Kouwen, N., Bingeman, A., Bellon, A., and Zawadzki, I.: Operational issues: Real-time correction and hydrological validation of radar data, Preprints, Sixth Int. Symp. on Hydrological Applications of Weather Radar, Melbourne, Australian Bureau of Meteorology, CD-ROM, 2004.

Li, L. and Schmid, W.: Nowcasting of motion and growth of precipitation with radar over a complex orography, J. Appl. Meteor., 34, 1286-1300, 1995.

Maidment, D.: Handbook of Hydrology, McGraw-Hill, Inc., 1992.

Metta, S., Rebora, N., Ferraris, L., von Hardernberg, J., and Provenzale, A.: PHAST: a phase-diffusion model for stochastic nowcasting, J. Hydrometeorol., 10, 1285-1297, 2009.

Mishra, S. and Singh, V.: Soil Conservation Service Curve Number (SCS-CN) Methodology, Kluwer Academic Publisher, 2003.

Pessoa, M. L., Raael, L. B., and Earle, R. W.: Use of weather radar for flood forecasting in the Sieve river basin: A sensitivity analysis, J. Appl. Meteor., 32, 462-475, 1993.

Pierce, C. E., Collier, C. G., Hardaker, P. J., and Haggett, C. M.: Gandolf: A system for generating automated nowcasts of convective precipitation, Meteor. Appl., 341-360, 2000.
Roberts, N.: Assessing the spatial and temporal variation in the skill of precipitation forecasts from a NWP model, Meteor. Appl., 15, 163-169, 2008.

Rossa, A. M., Del Guerra, F. L., Borga, M., Zanon, F., Settin, T. and Leuenberger, D.: Radardriven Highresolution Hydro-meteorological Forecasts of the 26 September 2007 Venice Flash Flood, J. Hydrol., 394, 230-244, doi:10.1016/j.jhydrol.2010.08.035, 2010.

Šálek, M., Brezková, L., and Novák, P.: The use of radar in hydrological modeling in the Czech Republic case studies of flash floods, Nat. Hazards Earth Syst. Sci., 6, 229-236, doi:10.5194/nhess-6-229-2006, 2006.

Schröter, K., Llort, X., Velasco-Forero, C., Ostrowski, M., and Sempere-Torres, D.: Implications of radar rainfall estimates uncertainty on distributed hydrological model predictions, Atmos. Res., 100, 237-245, 2011.

Seed, A. W.: A dynamic and spatial scaling approach to advection forecasting, J. Appl. Meteor., 42, 381-388, 2003.

Siccardi, F., Boni, G., Ferraris, L., and Rudari, R.: A hydrometeorological approach for probabilistic flood forecast, J. Geophys. Res, 110, d05101, doi:10.1029/2004jd005314, 2005.

Silvestro, F., Rebora., N. and Ferraris L.: An algorithm for realtime rainfall rate estimation by using polarimetric radar: RIME, J. Hydrometeorol., 10, 227-240, 2009.

Silvestro, F., Rebora, N., and Ferraris, L.: Quantitative flood forecasting on small and medium size basins: a probabilistic approach for operational purposes, J. Hydrometeorol., 12, 14321446, 2011.

Vieux, B. E. and Bedient P. B.: Assessing urban hydrologic prediction accuracy through event reconstruction, J. Hydrol. , 299, 217-236, 2004.

Vivoni, E. R., Entekhabi, D., Bras, R. L., Ivanov, V. Y., Van Horne, M. P., Grassotti, C., and Hoffman, R. N.: Extending the predictability of hydrometeorological flood events using radar rainfall nowcasting, J. Hydrometeorol., 7, 660-677, 2006.

Vivoni, E. R., Entekhabi, D., and Hoffman, R. N.: Error propagation of radar rainfall nowcasting fields through a fully distributed flood forecasting model, J. Hydrometeorol., 46, 932-940, 2007.

WMO: Simulated real-time intercomparison of hydrological models, OHR 38, 241 pp., 1992.

Zappa, M., Jaun, S., Germann, U., Walser, A., and Fundel, F.: Superposition of three sources of uncertainties in operational flood forecasting chains, Atmos. Res., 100, 246-262, doi:10.1016/j.atmosres.2010.12.005, 2011. 